\title{
EL CONCEPTO DE RIESGO EN MEDICINA
}

\author{
Fernando Guzmán Mora, $M D^{1}$, Tc Med Carlos Alberto Arias Páez ${ }^{2}$ \\ ${ }^{1}$ Médico. Universidad del Rosario.Cirujano Cardiovascular. Hospital Militar Central. Abogado. \\ Universidad Militar Nueva Granada. Magistrado. Tribunal Nacional de Ética Médica \\ ${ }^{2}$ Médico. Universidad Militar Nueva Granada. Cirujano Cardiovascular. Hospital Militar Central. \\ Instructor ATLS. Asociación. Colombiana de Cirugía.
}

\begin{abstract}
Es bien sabido que el ejercicio de la medicina entraña riesgo; $y$ es un hecho que la práctica médica puede provocar lesión a bienes jurídicos protegidos por la ley. Debido a esta circunstancia, algunos abogados han inferido, con poca profundidad en el análisis, que la medicina es una actividad peligrosa. En este escrito se pretende demostrar porqué no es válida esa afirmación.
\end{abstract}

A lo largo de la historia la sociedad ha aceptado la existencia del médico y el ejercicio de su actividad como un beneficio. Los seres humanos no sabrían qué hacer si en la comunidad no contaran con el precioso recurso de la medicina. Las personas dedicadas a la profesión médica han sido siempre tratadas con especial consideración y aprecio, porque se reconoce en ellas su dedicación, su voluntad de servicio, su idoneidad y eficiencia. Y es esa aceptación social, debida en buena parte al altruismo y la responsabilidad inherentes a la práctica médica, la que la distingue de lo que, incluso para la sociedad, se denominan actividades peligrosas.

Efectivamente, mientras en la medicina el riesgo calculado es una forma normal y necesaria de desarrollar los principios más caros de solidaridad, bien común y ayuda al prójimo, en las actividades peligrosas el ejecutor mira generalmente sólo su propio beneficio: Conducir un automóvil o portar un arma son ejemplos de actividades peligrosas. Se conduce un vehículo automotor por propia comodidad o como medio para adquirir lo económicamente necesario para sí mismo y su familia. Se porta o se utiliza un arma de fuego para la defensa personal y para defenderse de otro ser humano por medio de la agresión mortal.
De modo que tenemos en la raíz misma del comportamiento un móvil diferente, opuesto: mientras el médico aspira a servir, a curar, a restablecer la salud del prójimo, el hombre armado aspira a todo lo contrario, así sea sólo en caso de necesidad. Equiparar a los dos sujetos para introducir la profesión médica en la categoría de las actividades peligrosas es, por decir lo menos, un acto de irresponsabilidad intelectual.

Claro está que el médico puede obrar culposamente $y$, en ese caso, debe responder por el daño causado. Pero este es otro asunto. Por culpa se entiende una forma de conducta irregular en la cual no media una intención de dañar, pero que viola preceptos de prudencia, conocimiento, pericia y diligencia al efectuar la acción. A esto se puede sumar la falta de seguimiento de reglas aceptadas de la acción en el momento en que ésta se efectúa.

En el delito culposo se habla de una ilicitud, generalmente inconsciente. Cuando por consecuencia de un tratamiento se ocasione un daño en la integridad de la persona, la actuación del médico no será culposa si se encontraba dentro del riesgo previsto.

Cualquier tratamiento médico y quirúrgico es potencial causa de daño a la integridad del paciente. Ni la efectiva y humilde aspirina escapa a esta afirmación, pues ella puede producir la activación de una úlcera gástrica que lleve a hemorragia masiva, o puede ocasionar una reacción orgánica letal en algunos niños, que se conoce como el síndrome de Reyé. Su ingesta excesiva es la principal causa de intoxicación en niños, en quienes produce una severa acidosis metabólica. 
Las vitaminas, tan populares y apreciadas hasta por el farmaceuta que ilegalmente las fórmula, pueden también ser causa de alteraciones inmanejables: la vitamina A, al acumularse, puede llevar a síndromes de hipertensión endocraneana y a daño hepático; la vitamina $\mathrm{K}$ en sobredosis puede ocasionar serias alteraciones de coagulación.

$\mathrm{Ni}$ qué decir de los actos intervencionistas sobre el enfermo. La radioterapia para el cáncer ocasiona con frecuencia lesiones en órganos vecinos al comprometido por el tumor. Los métodos diagnósticos radiológicos que utilizan medios de contraste, pueden ocasionar la muerte en un paciente por reacción alérgica aguda debido a idiosincrasia de la persona. La cirugía, al ser el método terapéutico agresivo por excelencia, puede ocasionar complicaciones que le son propias y que pueden ser causa de muerte de quien ha sido sometido incluso a intervenciones menores.

Todo acto médico tiene un fundamento humano y científico. La medicina, como parte de las ciencias de la naturaleza y la sociedad se caracteriza por su racionalidad y su objetividad. Esta racionalidad está constituida por conceptos, juicios y raciocinios, y no solamente por sensaciones, imágenes o pautas estereotipadas de conducta; sus ideas son capaces de combinarse de acuerdo con algún conjunto de reglas lógicas, con el fin de producir nuevas ideas. Éstas, a su vez, no se amontonan caótica o cronológicamente, sino que se organizan en sistemas de ideas, esto es, en conjuntos ordenados de proposiciones (teorías).

En toda consulta, análisis, diagnóstico, opinión, interconsulta, junta médica, investigación, publicación o procedimiento especial, el médico aplica el método científico. Es decir, aquel procedimiento para descubrir las condiciones en que se presentan sucesos específicos, aplicando la lógica a los hechos observados. A través de este mecanismo se plantean problemas, se prueban hipótesis e instrumentos de trabajo investigativo. Aunque no lo haga de manera consciente, el médico aplica en forma permanente sus conocimientos de estadística. Juega con leyes de probabilidades, estudia variables, analiza su interdependencia y relación, en fin, convierte el oficio en profesión y el arte en ciencia. Esta es la diferencia con los empíricos.

Cualquier miembro de la sociedad que acuda a otro en búsqueda de diagnóstico, tratamiento, pronóstico y recomendaciones que vayan a incidir sobre su cuerpo y su salud, se está convirtiendo en un paciente. Y quien ejerza su conocimiento buscando satisfacer esta petición está ejerciendo como médico. Si partimos de las definiciones previas, cuando quien actúa como médico es una persona calificada por la sociedad como idónea para ejercer la profesión, se cumplen los requisitos legales que hacen del acto un contrato legal y una relación profesional y ética, con todas sus consecuencias sociales. Si el acto médico puede solamente ser ejercido por el profesional universitario legalmente reconocido, cualquiera que practique actividades de diagnóstico, pronóstico, tratamiento, rehabilitación o similares, está ejerciendo la medicina en forma ilegal.

Esto quiere decir que la práctica de un acto médico debe estar respaldada por el ejercicio legítimo de un derecho y el cumplimiento de un deber por parte del profesional médico debidamente graduado y habilitado por la legislación nacional, en beneficio del paciente. Como todo acto médico implica un riesgo, para que este riesgo no sea considerado una agresión, su finalidad debe ser de ayuda al organismo enfermo y debe basarse en ciertas normas: licitud, ejecución típica, seguimiento de normas científicas universalmente aceptadas y profesionalismo.

Actualmente el derecho penal viene haciendo unos aportes importantes al esclarecimiento del asunto, contextualizando el comportamiento dentro de la categoría de 'rol social'. Desde esta perspectiva, ha de tenerse al ejercicio médico como un papel determinado, que la comunidad en el plano social y el Estado en el plano institucional, han acordado como permitido y necesario, así deba reconocerse y aceptarse la inclusión del riesgo dentro de su práctica.

Esa valoración es la que permite diferenciar en el derecho penal cuando el comportamiento objetivamente visto, encuadra en el tipo o descripción legal del delito; por tal razón, la incisión que con el bisturí realiza el cirujano, mal puede considerarse como una 'lesión' en el sentido médico legal (daño físico en el cuerpo o a la salud).

Como lo aclara Jackobs: "[...] el mundo social no está ordenado de manera cognoscitiva, con base en relaciones de causalidad, sino de manera normativa, con base en competencias, y el significado de cada comportamiento se rige por su contexto. Por tanto, el hecho de que un comportamiento cause de modo 
cognoscible un resultado pernicioso, per se no quiere decir nada."

Es, ni más ni menos, eso lo que ocurre en la profesión médica. Aparentemente (cognoscitivamente) una herida en el abdomen es una 'lesión', pero normativamente esa herida es quirúrgica $y$, por tanto no dañina o dañosa, sino todo lo contrario: herida benéfica gracias a la cual se pretende salvar la vida del paciente. No es, pues, una conducta que se 'justifique' (nada debe justificar el cirujano ante la ley penal o la sociedad), sino una conducta que no es 'típica' (considerada por la ley penal como delito).

De acuerdo con Jackobs: "un comportamiento que genera un riesgo permitido se considera socialmente normal; por lo tanto, los comportamientos que crean un riesgo permitido no son comportamientos que hayan de ser justificados".

El Estado se encarga, entonces, de dar el espaldarazo a la decisión de la comunidad y acepta al médico como un integrante que, lejos de ser peligroso, es benéfico para la sociedad. Obviamente se regula su actividad y se le exige un nivel de competencia que el mismo Estado certifica (título universitario); pero una vez que el médico se encuentra ejerciendo legalmente, su actividad queda regulada en esencia por su criterio personal y profesional.

Por ser sumamente ilustrativo, se puede citar de nuevo al profesor alemán: "... desde luego hay ámbitos jurídicos - algunos de ellos con potencial de peligro - en los que no es necesaria una regulación jurídica, porque puede obtenerse un alto estándar de seguridad de otra forma, por ejemplo, planteando exigencias especiales respecto de la formación de quienes actúan en ellos, como sucede en el ámbito médico.

En la mayoría de los casos, probablemente concurran además otras razones a la hora de renunciar a una regulación: tomando de nuevo como ejemplo el ámbito médico, la necesidad de un alto grado de individualización sólo permitiría establecer regulaciones a tal nivel de abstracción que acabarían siendo carentes de contenido. Además, tampoco es conveniente fijar legalmente un estándar en aquellos casos, como - de nuevo - en el campo de la medicina, en los que se produce una evolución permanente. Por ello, la regla profesional reconocida, lex artis, sustituye en estos ámbitos al precepto jurídico."
De esta manera se explica que el riesgo inherente al acto médico, sea asumido como normal por el paciente y no por el mismo médico quien, dicho de paso, debe calcularlo con precisión, con el fin de no exponer al paciente a un peligro mayor del necesario. Si traspasa este límite previsto, estaría obrando culpablemente.

\section{Consentimiento para el riesgo}

El paciente debe manifestar su consentimiento, bien sea de manera personal o a través de la persona que tenga su representación legal o que le sea más allegada, en los casos en que no pueda hacerlo directamente (minoridad, inconsciencia, alteración mental). Este consentimiento, otorgado para el acto médico, será valido en la medida en que se obtenga de una persona bien informada.

El médico tiene la obligación de mantener al paciente permanentemente informado y la información debe ser completa y precisa, siempre que sea posible darla. Habrá eventos en los cuales el médico, según prudente juicio, mejor deba abstenerse de dar una información que lleve al paciente a un estado físico o mental peor de aquel en que se encuentra. Pero si necesita la autorización del enfermo o de sus familiares para proceder clínicamente, esta en la obligación insoslayable de advertir el riesgo previsto, so pena de responder por él (artículo 16, Ley 23 de 1981).

Esta obligación deriva, claramente, del principio de libertad que hace de los actos del ser humano una manifestación de su soberana determinación personal. La autonomía que consagra y ampara la Constitución Política de Colombia como desprendimiento de esa libertad (artículos 13, 16 y 28), está implícita en las decisiones de quien se somete a un tratamiento médico.

Incluso, como se ha recordado por la Corte Constitucional, cuando esas decisiones "se toman de manera imprudente o en perjuicio de la salud. Esta perspectiva considera peligrosa la posibilidad de reservar un derecho de intervención en aquellos eventos en los cuales el médico piensa que el paciente ha tomado la opción equivocada. El principio de autonomía permanece incólume aun cuando la persona elige de manera consciente un camino que no conduce al beneficio de su mejor interés. Esto es lo que en filosofía se conoce como 'voluntad débil'. El derecho de los fumadores, por ejemplo, se funda en este tipo de justificación. No 
obstante la certeza del mal que produce el consumo del cigarrillo, se supone que el valor de la autonomía está por encima del perjuicio que pueda derivarse de la opción escogida" (Sentencia T- 401/94).

En esta forma se entiende que ante el riesgo, más o menos grande, que entraña toda intervención médica, corresponde al paciente, y no al médico, tomar la decisión y asumirlo. Si el paciente no está de acuerdo con la opción que el médico le presenta, puede elegir libremente a otro profesional que se haga cargo del asunto. Si el paciente propone o escoge una opción con la que el médico tratante no convenga, puede retirarse del tratamiento, como lo autoriza el artículo 7 de la Ley 23 de 1981, que a la letra dice:

"[...] cuando no se trate de casos de urgencia, el médico podrá excusarse de asistir a un enfermo o interrumpir la prestación de sus servicios, en razón de los siguientes motivos: [...] c) que el enfermo rehúse cumplir las indicaciones prescritas."

En la órbita penal hay necesidad de hacer una aclaración: no hay delito en atentar contra sí mismo, contra su salud o contra su propia vida. El reconocimiento del principio de autonomía ha sido permanente en el derecho penal, que solamente castiga los comportamientos que atenten contra otra persona o contra la sociedad. El artículo 327 castiga la inducción o la ayuda al suicidio que 'otro' preste al suicida, quien (dicho sea de paso) actuará según su designio, sin miedo a la sentencia del juez. Pero el médico que lo induzca o que le preste ayuda será castigado con prisión de dos a seis años.

Obviamente, el principio de autonomía del paciente tiene un límite: el del actuar ético del médico, que ha jurado servir a la humanidad respetando la Ley. Por ello, cualquier determinación del paciente, por más 'libre y autónoma' que se pretenda, no obliga a un profesional que considere esta decisión absurda o contraproducente. Secundar al enfermo en su irresponsabilidad es participar conscientemente del daño que esa decisión pueda producirle.

\section{Previsión y toma de decisiones}

Prever es la capacidad, por parte de un ser humano de cultura, educación e inteligencia promedio, de pronosticar un resultado futuro aproximado cuando se efectúa una acción. Es anticipar un resultado posible, efectuando un pronóstico en relación con una conducta. Desde el punto de vista del ejercicio médico, la capacidad de prever razonablemente se juzga de acuerdo con lo que hubiese hecho un médico de similares características, educación y altura académica de la que posee aquel que ocasiona un daño. Lo anterior, se debe debe a los diferentes grados de complejidad que pueden conllevar los actos médicos, cuya naturaleza hace imposible asimilar la previsión a la de un ser humano 'normal', o incluso poner en la misma escala a sujetos con diferentes especialidades.

Y si bien es cierto que a mayor cantidad y calidad de estudios y especialidades, debe exigirse un mayor cuidado, no se puede llegar al extremo de suponer la previsibilidad del ciento por ciento de las posibilidades, por razones obvias: En el cuerpo humano y en la acción terapéutica siempre está presente, de una u otra forma, el azar. La medicina no es una ciencia exacta, y no todos los pacientes responden de idéntica manera.

De otro lado, prevenir es tomar todas las disposiciones necesarias para que un resultado dañoso no tenga efecto. La toma de decisiones es la selección de un curso de acción entre alternativas. Constituye entonces el eje de la planeación.

El proceso que conduce a la toma de una decisión incluye:

1. Elaboración de premisas. Basada racionalmente, entendiendo las alternativas y con el franco deseo de llegar a soluciones. La racionalidad se limita por factores como tiempo, información y certeza.

2. Identificación de alternativas. Se basa en la más correcta información y en la ayuda de los subalternos e iguales. Factor limitante a estas alternativas es aquello que se opone al logro de un objetivo deseado. Una vez superado, se puede seleccionar el mejor curso de acción.

3. Evaluación de alternativas. Debe hacerse a la luz de factores cuantitativos (medibles) y cualitativos (intangibles). También debe tenerse en cuenta al análisis marginal (ingresos adicionales vs. costos adicionales) y la relación costo-beneficio.

4. Selección de una alternativa. Para esto se puede utilizar la experiencia (bien entendida como el aprovechamiento de las lecciones del éxito y el fra- 
caso), la experimentación (que tiene peligros por sus costos) y la investigación analítica (utilizando el método científico y el desarrollo de modelos).

Las decisiones pueden ser programadas, cuando aplican a problemas de rutina o estructurados; y no programadas, para situaciones nuevas, mal definidas y de naturaleza no repetitiva. Las decisiones en condiciones de incertidumbre se pueden enfocar como:

1. Análisis de riesgos, basados en la opinión de los especialistas del grupo tratante.

2. Árboles de decisión, que evalúan los puntos de decisión, los acontecimientos fortuitos y las probabilidades existentes, con lo cual se pueden evaluar las alternativas principales, mostrando los aspectos críticos y un proceso de razonamiento lógico en la decisión.

Como se aprecia, la toma de decisiones es un proceso intelectual complicado, que debe juzgarse a la luz de cada caso individual, atendiendo a la norma de excelencia del momento y a la teoría de probabilidades respectiva.

\section{Riesgo y estadística en medicina}

La estadística es el conjunto de técnicas a través de las cuales se recogen, ordenan y analizan datos cuantitativos, con el objeto de tomar decisiones. Ej.: porcentaje de muerte en pacientes con infarto agudo del miocardio que no reciben tratamiento hospitalario; meses de sobrevida luego de quimioterapia con la droga ' $x$ ' en pacientes con linfoma estado IV; incidencia de leucemias en personas mayores de 15 años con síndrome de Down; etc.

La inferencia estadística se refiere a los métodos mediante los cuales se toman decisiones sobre una población, basados en muestras. Estas decisiones se toman en condiciones de incertidumbre $y$, por lo tanto, se requiere del uso de los conceptos de probabilidad. Ej.: de una muestra de 100 individuos entre los 25 y 30 años en una población de Nariño, se encuentra que 30 de ellos presentan gastritis crónica atrófica con metaplasia intestinal, lo cual los predispone a la aparición de cáncer gástrico. De los 30, nueve desarrollan un tumor maligno en el curso de los siguientes diez años. Por lo tanto, se concluye que en esa población existe un altísimo riesgo de cáncer del estomago y por lo tanto se decreta una búsqueda masiva de tumores incipientes mediante endoscopia gástrica en toda la población mayor de 20 años.

Los métodos estadísticos son variables. Los pertenecientes a la 'estadística clásica' efectúan inferencias a partir de datos numéricos, sin ningún tipo de opinión personal del analista. Ej.: Los pacientes con distrofia muscular de tipo Duchenne, mueren antes de los 25 años sin importar el tratamiento que se instaure.

En cambio, el análisis bayesiano involucra el juicio del especialista y estudia los resultados posibles, basado en alternativas. Ej.: se encontró en la ciudad de Edimburgo (Escocia), que cada drogadicto con heroína le costaba al país una cantidad $\mathrm{X}$ de dinero, debido a las complicaciones de la inyección de estimulantes endovenosos con agujas contaminadas, que infectaban su organismo y, particularmente, una de las válvulas cardíacas (tricúspide). Basados en lo anterior, resultaba más conveniente para el país repartir agujas estériles entre los drogadictos en forma masiva, tres veces por semana, para disminuir la infección valvular cardíaca, cuyo manejo es complicado y muy costoso.

Los datos en medicina, en términos generales, corresponden a 'variables continuas'. Éstas, a diferencia de las 'variables discretas' (que tiene valores en puntos específicos a lo largo de una escala), pueden suponer valores en cualquier punto entero o fraccionario de la mencionada escala, y sus datos se generan por el proceso de medición.

Ejemplo de variable discreta: De un lote de diez marcapasos cardíacos se encuentran dos defectuosos.

Ejemplo de variable continua: Se conoce que el tiempo de duración de un marcapasos colocado en un paciente es de 10 a 15 años. Esto quiere decir que, en cualquier momento entre el año 10 y el año 15, puede fallar el aparato electrónico.

Debido a que la variable continua puede tomar cualquier valor fraccionario en un determinado rango de valores, con una probabilidad indefinida de valores posibles, éstos no pueden agruparse con su respectiva probabilidad al frente (solamente entre el cero y el uno, ya existe un numero indefinido de valores probables). Por lo tanto, se expresa en forma de 'curva de probabilidad', o función de densidad de probabilidad, la cual cobija por debajo de su curva, las probabilidades para cada valor. 
Ejemplo: La probabilidad de parálisis de miembros inferiores (paraplejía) en un paciente sometido a una intervención sobre la aorta torácica que implica clampeo (cierre) de la misma, es de porcentaje variado entre 3\% y 33\%, en diversas series de estudios clínicos. Esto ocuparía un área determinada de probabilidad bajo la curva. Si a esto se añade que el enfermo presenta lesiones obstructivas arterioscleróticas en las arterias viscerales, la probabilidad de lesión puede aumentarse de $15 \%$ a $70 \%$, con un área diferente bajo la curva.

La curva estadística típica es la denominada 'distribución normal de probabilidad' y se representa en forma de campana. Esto obedece a que se conoce que las mediciones obtenidas en procesos al azar tienen esta forma de distribución y las que no la tienen y siguen otras distribuciones (binomial, Poisson), pueden aproximarse a dicha distribución normal mediante fórmulas específicas.

Los datos obtenidos de estudios deben ser descritos de alguna forma. Por esto, se trata de buscar un valor que represente dicho grupo, es decir, un promedio. Ej.: Desde el punto de vista semiológico, se desea describir a los pacientes con síndrome de Marfan que ingresan a los consultorios de medicina interna. Se dice entonces que el paciente con este síndrome es generalmente alto, delgado, con aracnodactilia (dedos delgados y largos) y con frecuencia presentan otra enfermedad asociada: la disección de aorta.

Por supuesto, sabemos que puede haber pacientes altos y con aracnodactilia que no tienen el síndrome de Marfan, en la misma forma en que puede existir disección de la aorta no asociada a este síndrome. Así mismo, se observan casos de Marfan en personas de estatura promedio y sin disección de aorta. Todas estas combinaciones son posibles. Sin embargo, el promedio, el típico caso de Marfan, cumple en general con los requisitos descritos inicialmente.

Ej.: El paciente típico con apendicitis aguda presenta una serie de síntomas como dolor abdominal, fiebre, vómito y dolor en el cuadrante inferior del abdomen. $Y$ aunque algunos enfermos presentan apendicitis sin fiebre, o tienen dolor abdominal asociado a fiebre y vómito sin que corresponda necesariamente a una apendicitis aguda, el paciente característico tiene los signos y síntomas anotados.
Lo anterior quiere decir que, al evaluar el riesgo de un tratamiento, debe tenerse en cuenta el tipo de paciente, el campo de especialización del médico que lo atiende, los recursos de los cuales dispone, el momento de la enfermedad en el cual consulta, lo típica que sea la presentación de su enfermedad y otro número de variables.

Quiere esto decir que juzgar el caso individual es sumamente difícil. No se puede condenar por las complicaciones del tratamiento simplemente porque ellas ocurran. El nivel de abstracción del juez y sus conocimientos específicos deben ser de tal magnitud que le permitan emitir su sentencia con el máximo de seguridad posible y con la mayor tranquilidad de conciencia.

\section{Ejercicio profesional, riesgo y confianza social}

Los médicos, en general, siguen la norma ética kantiana: en lugar de decir "Haz aquello que te haga feliz", Kant dice: "Haz aquello que te haga digno de ser feliz".

Sólo las cosas tienen precio. La persona humana tiene dignidad. Los seres racionales, por lo tanto, nunca son medios; son fines en sí mismos. Por ello, debe tratarse siempre a la humanidad, tanto en la persona propia como en la de los demás, como un fin, sin servirse de ella exclusivamente como medio. Si se considera al ser humano que se tiene en las manos como un fin, y ejerciendo la libertad se obra con la voluntad excelente de hacer el bien, colocando todos los elementos posibles para ello, el acto médico será la manifestación de una ética universal que no admite contradicción.

Todo procedimiento médico tiene riesgos. El problema actual es que se tiende a trasladar dicho riesgo al médico, sin una razón suficiente. Anteriormente el enfermo era consciente de su estado y asumía las consecuencias del tratamiento, sin inculpar al médico por el fracaso. Era una posición responsable que se basaba en el principio de la buena fe recíproca: el paciente era sincero con el médico y le descubría su cuerpo y alma; iba a él en busca de ayuda y confiaba en que el médico, a su vez, haría lo que estuviera a su alcance para obtener la recuperación de la salud. Si no se lograba, no había reclamo. Ambos sabían que se había intentado y hecho todo lo posible. 
Hoy, infortunadamente, el mundo ha cambiado de la confianza recíproca al provecho personal. Las relaciones entre las personas ya no se fundan en la 'bona fides' de los antiguos, sino en su seguridad. Y este cambio en el comportamiento social ha hecho más difícil el desarrollo de actividades que, como la que nos ocupa en este escrito, entrañan riesgo.

¿Cómo preservar la seguridad del paciente cuando necesariamente debe intervenirse sobre su organismo? $\mathrm{Al}$ médico se presenta la persona, por regla general, cuando tiene problemas de salud. El paciente es consciente de que su estado de salud puede empeorar si no acude a la consulta. Si lo hace, es luego de resolver una disyuntiva: no voy al médico y asumo las consecuencias, o voy en busca de su ayuda.

¿Quién asume entonces dichas consecuencias cuando el paciente concurre a la consulta? ¿Por qué razón se le traslada el riesgo al médico? ¿Simplemente porque se le esta pagando algún dinero? En el contrato que se establece ¿asume el galeno la responsabilidad por el riesgo? ¿Debe asumirla como contraprestación del dinero recibido?

Consideramos que no. Consideramos que el amparo de la salud corresponde a la persona misma y que, si quiere trasladar el riesgo, debe buscar una compañía de seguros. En el mejor de los casos así se viene haciendo... sólo que esta práctica encarece el servicio, por la razón que ya hemos reseñado: el asegurador paga y como paga debe trasladar el costo para que su negocio siga siendo rentable, demandando al médico para intentar la recuperación de lo pagado, por lo que el médico gasta dinero para defenderse y busca medidas de protección al futuro, encareciendo con ellas el servicio. Y esta espiral no se detiene sino cuando haya consciencia del círculo vicioso que ha generado el abandono del principio de confianza.

La ciencia no es infalible y el Estado no siempre es garantista de los hechos de sus asociados. Mal pudiera entonces el personal de salud que trabaja en los hospitales y consultorios, ser infalible ni garantista de un hecho que implique riesgo para la integridad de una persona. Aun contando con los recursos tecnológicos y humanos más complejos, puede equivocarse. Pero la equivocación no entraña responsabilidad, sino cuando obedece a algún tipo de culpa por negligencia, descuido, imprudencia o impericia.

La legislación, la doctrina de los autores, y la jurisprudencia de los tribunales deben pregonar, en principio, la inocencia del médico y demás profesionales de la salud; deben decir que, en principio, se considera que obran de buena fe y que si ocurre un daño, no se recupera la salud o simplemente no se obtiene el resultado esperado, el paciente debe asumir este fracaso, a no ser que medie un acto culposo por parte del médico. Mientras se insista, como por ejemplo viene haciéndolo alguna jurisprudencia de nuestro Consejo de Estado, en que la carga de la prueba corresponde al médico, se estará obligando al personal de la salud en Colombia a tomar medidas de protección extremas, que en nada beneficiaran a los usuarios.

\section{Bibliografía}

1. Guzmán F, Franco E, Morales MC. El Riesgo en Medicina. En Guzmán F, Franco E, Rosselli D. La Práctica de la Medicina y la Ley. Biblioteca Jurídica Diké.l Edición. Medellín, 1996.

2. Guzmán F, Franco E, Arrázola F. El Deber de Cuidado en Medicina. En: Guzmán F, Franco E, Rosselli D. La Práctica de la Medicina y la Ley. Biblioteca Jurídica Diké. 1 Edición. Medellín, 1996.

3. Guzman F, Franco E, Morales MC. El Riesgo en Medicina. Rev Col Mayor Ntra Sra del Rosario 1996; 89 (571-572): 79-87.

4. Guzmán F, Franco E. El riesgo en medicina y el concepto de "actividad peligrosa". Rev Col Cardiología 1997; 5: 385-390.

5. Guzmán F, Franco E. Riesgo, negligencia e imprudencia en urgencias.En: Peña G, Guzmán F. Trauma: Temas Básicos. Federación Médica Colombiana. Bogotá, 1999.

6. Guzmán F. La regulación del riesgo y la posición de garante del cirujano. Carta Quirúrgica 2002; No.8 Pág. 1-2.

7. RIESGO EN MEDICINA Guzmán, F. Franco, E. DERECHO MÉDICO COLOMBIANO. TOMO I. VOL 1 Y 2. RESPONSABILIDAD CIVIL MÉDICA. Biblioteca Jurídica Diké. Medellín, 2004.

8. PERSONAS DE ALTO RIESGO Guzmán, F. Franco, E. DERECHO MÉDICO COLOMBIANO. TOMO I. VOL 1 Y 2. RESPONSABILIDAD CIVIL MÉDICA. Biblioteca Jurídica Diké. Medellín, 2004.

9. RIESGO EN MEDICINA Guzmán, F., Franco, E., Saavedra, E. DERECHO MÉDICO COLOMBIANO. TOMOS I, II Y III. RESPONSABILIDAD DISCIPLINARIA ÉTICO MÉDICA. Universidad Libre. Bogotá. 2007. 